\title{
REKOMENDASI TEKNIK MENINGKATKAN PRODUKTIVITAS MANAJEMEN SEKOLAH
}

\section{Fachriyah Al Mahi}

Universitas Nahdlatul Ulama Sidoarjo

\section{LATAR BELAKANG}

Kepala sekolah atau wirausahawan pendidikan memainkan peran penting dalam mempertahankan kehidupan yang beradab. Pimpinan pendidikan yang tepat dapat secara signifikan mengurangi kekacauan yang tidak perlu yang ada dalam kehidupan sehari-hari. Untuk operasi yang efektif dari lembaga seperti sekolah, kepala sekolah sangat penting. Kepala sekolah adalah sistem kode perilaku, perilaku, dan hukuman tertentu untuk mengatur siswa dan membuat sekolah terorganisir dengan baik. Untuk membuat proses belajar mengajar efektif, lingkungan kelas harus menguntungkan dan tepat waktu. Di dunia yang terus-menerus bergerak maju, sungguh mengherankan bahwa siapa pun dapat menemukan waktu untuk lebih dari sekadar bekerja, terutama ketika Anda bertanggung jawab mengelola seluruh sekolah 
sebagai kepala sekolah atau wirausahawan pendidikan. Berikut adalah beberapa tips untuk meningkatkan produktivitas Anda sebagai kepala sekolah dan pengusaha pendidikan yang sibuk.

\section{JURNAL CATATAN}

Pemimpin sekolah sebisanya tegas, toleran terhadap bawahannya dan mengayomi. Pendidikan adalah catatan masa lalu dan pengajaran masa kini untuk masa depan bangsa. Pendidikan adalah menyampaikan ilmu dan mentransformasi orang lain menjadi lebih baik (Fidiana, Istiana, Rosyidah, \& Purnomo, 2017). Ini adalah kegiatan yang hebat karena merefleksikan hari membantu pemimpin sekolah yang efektif fokus pada hasil dan mulai memahami mengapa semuanya berjalan atau gagal. Plus, siapa tahu, Anda mungkin ingin menulis buku suatu hari! (Bauer, 2019).

\section{SISWA ADALAH PRIORITAS UTAMA}

Kesabaran dan komunikasi yang baik dengan masyarakat sekitar adalah kunci untuk dapat mengatasi masalah dan bisa bangkit dari keterpurukan manajemen pendidikan. Prinsip utama dan kepemimpinan wirausaha pendidikan adalah disiplin, kreatif, cerdas dan ulet (Qori'ah, Sholichah, Purnomo, \& Rosyidah, 2017). Kepala 
sekolah yang berhasil menjadikan siswa sebagai prioritas nomor satu mereka. Mereka tidak pernah menyimpang dari jalan itu. Semua harapan dan tindakan diarahkan untuk siswa yang lebih baik baik secara individu maupun secara keseluruhan. Keselamatan, kesehatan, dan pertumbuhan akademik siswa adalah tugas kami yang paling mendasar. Setiap keputusan yang dibuat harus mengambil dampak yang akan terjadi pada siswa atau kelompok siswa. Kami ada untuk memelihara, menasihati, mendisiplinkan, dan mendidik setiap siswa. Sebagai kepala sekolah, Anda tidak boleh melupakan fakta bahwa siswa harus selalu menjadi titik fokus kami (Meador, 2019).

\section{WIRAUSAHA EDUKASI}

Menjaga hubungan baik dengan wali siswa melalui melaksanakan janji dan pelayanan yang baik adalah bagian dari promosi wirausaha (Asitah, Usmawati, Rosyidah, \& Purnomo, 2017). Edupreneur atau educational entrepreneur berasal dari dua kata yaitu education bermakna pendidikan dan entrepreneur bermakna pengusaha atau wirausahawan. Ada juga yang menyamakan istilah edupreneur dengan istilah teacherpreneur (Purnomo, 2017). Toleransi, bekerja sama, bertanggungjawab, dan amanah 
adalah prinsip wirausaha pendidikan (Nahdiyah, Amrina, Purnomo, \& Rosyidah, 2017).

\section{JARINGAN}

Jika Anda berada dalam ruang hampa bakat alami hanya akan membuat Anda sejauh ini. Para pemimpin sekolah yang efektif terhubung dengan orang lain yang dapat membantu mereka mempercepat pertumbuhan mereka dan meneruskan pengetahuan mereka juga. Cari orang yang berusia 5-10 tahun melakukan apa yang ingin Anda lakukan di masa depan. Bagaimana Anda bisa menambah nilai dalam hidup mereka untuk menghabiskan waktu belajar dari mereka? (Bauer, 2019). Cara memimpin sekolah adalah senantiasa musyawarah serta sharing bersama para guru (Yuniarti, Kautsari, Sholichah, Purnomo, \& Rosyidah, 2017).

\section{PERTAHANKAN SIKAP POSITIF}

Dari semua kiat untuk Kepala Sekolah, ini terdaftar pertama karena biasanya yang paling penting. Anda mengatur panggung untuk sekolah Anda sama seperti guru Anda mengatur panggung untuk ruang kelas mereka (Drewitt, 2017). Pendidikan Indonesia membutuhkan peningkatan akses, mutu dan relevansi 
pendidikan untuk memberi manfaat membangun bagi pendidikan dan rakyat Indonesia (Irawan et al., 2018).

\section{IMPLEMENTASI TAAT TUHAN}

Guru harus bisa membangun generasi muda untuk masa depan. Hiduplah untuk mengamalkan ilmu (Sholichah, Istiqomah, Rosyidah, \& Purnomo, 2017). Hubungan pendidikan antara guru dan murid itu seperti aliran listrik dengan lampu. Bagaimana lampu itu bisa menyala kalau aliran listriknya juga mati ?. Bagaimana murid itu bisa berprestasi sedangkan guru sendiri tidak pernah berprestasi dan mendoakan (Fidiana et al., 2017). Setiap manusia hamba Tuhan yang memiliki ilmu selayaknya harus mengamalkan ilmu tersebut (Asitah et al., 2017).

Pendidikan adalah kunci untuk membuka pintu emas kesuksesan. Wirausaha pendidikan dengan motivasi bisnis dengan Allah Ta'ala sebagai bentuk kenyamanan untuk ibadah. Tips mengelola institusi pendidikan adalah niat mendidik dan berjuang karena Allah ta'ala. Niscaya rintangan sebesar apapun akan terasa ringan dihadapan kita. Melihat anak mengenal Allah Ta'ala dan sukses akhlak dan pengetahuannya merupakan kebahagiaan 
pendidik (Yuniarti et al., 2017). Prinsip pendidikan adalah sosial. Sebagai seorang guru, kita harus memiliki kepedulian sosial (Asitah et al., 2017).

\section{AJARKAN PROSEDUR DENGAN BAIK}

Membuat prosedur yang baik dan tepat tidak cukup. Mereka harus diajarkan kepada siswa dengan baik juga. Empat langkah yang terlibat dalam mengajar mereka adalah:

a. Jelaskan prosedurnya dengan jelas;

b. Praktekkan dengan siswa-siswa;

c. Perbaiki bagian yang dilakukan dengan tidak benar;

d. Ulangi terus-menerus sampai mereka melakukannya dengan cara yang benar

Jika Anda tidak meluangkan waktu untuk mengajarkan prosedur dengan benar, siswa mungkin tidak mengikuti mereka yang mengarah pada frustrasi total (Edsys, 2016).

\section{AKUI DAN HORMATI PARA PENDAHULU ANDA}

Perlu diingat bahwa hantu masa lalu dapat menghantui sekolah (Drewitt, 2017).

\section{BERTANGGUNGJAWAB}

Ingatlah bahwa Anda bertanggung jawab atas semua yang terjadi di sekolah Anda. Jangan 
gunakan 'salahkan' dalam situasi apa pun, alihalih tanyakan pada diri sendiri "Apa tanggung jawab saya dengan masalah ini dan pemikiran strategis atau tindakan strategis apa yang dapat saya ambil untuk memperbaiki situasi?" (Driscoll, 2018).

\section{INGAT ATURAN LAYANAN PELANGGAN \# 1}

Ketika menyangkut siswa, dosen, dan orang tua Anda, Anda harus selalu membunuh mereka dengan kebaikan (Drewitt, 2017). Siswa perlu memahami apa yang diketahui dan apa yang diminta untuk memiliki kemampuan menjawab (Suci et al., 2018). Guru merupakan seorang pendidik dan pengajar sekaligus sebagai pembentuk kepribadian siswa yang unggul, berwawasan dan baik (Maula et al., 2018).

\section{BERSIKAP POSITIF}

Pemimpin sekolah dan wirausaha pendidikan seharusnya senantiasa menikmati proses karena tidak ada hal yang besar yang tidak dilakukan dari hal yang kecil. Semua butuh proses, karena kesuksesan tidak datang secara langsung tanpa berproses (Maula, Mufidah, Rosyidah, \& Purnomo, 2017). Praktik terbaik kepemimpinan sekolah yang konstruktif termasuk membuat orang merasa seperti mereka 
memberikan kontribusi positif kepada sekolah sambil secara bersamaan memberi tahu mereka bagaimana mereka dapat meningkatkan kinerja mereka. Para pemimpin yang bertemu dengan guru dan / atau siswa harus terlebih dahulu memberi tahu mereka apa yang mereka lakukan dengan benar. Mereka harus dapat mengatakan tiga hal positif tentang kinerja seseorang sebelum mendapat kritik yang membangun. Tujuannya adalah membuat orang ingin meningkatkan, dan moral buruk dapat menyebabkan orang dewasa berhenti dari pekerjaan dan siswa untuk berhenti belajar (Watanabe-Crockett, 2018).

\section{MENEKANKAN MANAJEMEN WAKTU YANG EFISIEN}

Sedini kelas tiga, siswa-siswa dapat didorong untuk menggunakan jadwal dan perencana harian. Bantu siswa Anda untuk "berhubungan" dengan waktu dengan memperkirakan berapa lama suatu tugas, menentukan waktu tugas, dan membandingkan waktu dengan perkiraan tersebut. Tetapkan waktu untuk tugas-tugas tertentu yang seringkali memakan waktu terlalu lama. Bermain "beat the clock" membuat tugas terasa lebih seperti permainan dan meningkatkan kesadaran siswa akan waktu (Springer, 2019). 


\section{BERURUSAN DENGAN KELUHAN}

Panduan keluhan ini akan membantu Anda menerapkan prinsip-prinsip sederhana dan luas dalam cara Anda menangani keluhan (Educational Leaders, 2019). Tips kelola sekolah adalah senantiasa belajar dan bekerja keras. Bersabarlah dengan masalah, sesungguhnya didalam kesulitan ada kemudahan (Sholichah et al., 2017).

\section{RENUNGAN PENDIDIKAN}

Hasil penelitian menunjukkan bahwa penerapan pembelajaran dapat meningkatkan prestasi siswa; dan tes menunjukkan bahwa prestasi belajar siswa kelas belajar lebih baik daripada siswa kelas konvensional (Iskandar, Rizal, Kurniasih, Sutiksno, \& Purnomo, 2018). Pendidikan itu sebuah perhiasan dalam kemakmuran dan tempat bernaung dalam kesengsaraan (Maula et al., 2017). Guru merupakan seorang yag memilki tugas mulia sebagai pendidik dan pengajar sekaligus sebagai pembentuk kepribadian siswa (Maula et al., 2018). Manajemen sekolah dilakukan dengan menerapkan standar kualitas dalam rekrutmen pengajar yaitu kedekatannya dengan amaliyah (Munjidah, Zannah, Purnomo, \& Rosyidah, 2017). 
Cari ilmu yang bermanfaat dan patuhi aturanaturan yang ada. Bijaksana dan pantang menyerah dalam belajar adalah kunci kesuksesan. Pendidikan adalah pelajaran yang harus kita pelajari setiap hari baik dari buku, lingkungan, teman, maupun keluarga agar kita tidak tertinggal (Qori'ah et al., 2017). 


\section{REFERENCES}

Asitah, N., Usmawati, D. Z., Rosyidah, E., \&

Purnomo, A. (2017). MI Hasyim Asy'ari IImu

Harus Terus Mengarus. In Wirausaha

Pendidikan Indonesia (Jilid 2). Sidoarjo:

UNUSIDA Press.

Bauer, D. (2019). 200 Tips for Effective School

Leaders. Retrieved June 17, 2019, from

https://www.betterleadersbetterschools.com/200

-tips-effective-school-leaders/

Drewitt, P. (2017). 25 tips for School Principals.

Retrieved June 12, 2019, from

https://www.linkedin.com/pulse/25-tips-school-

principals-paul-drewitt

Driscoll, M. (2018). 16 Success Tips for New 21st

Century Principals. Retrieved June 25, 2019, from https://thinkstrategicforschools.com/16success-tips-new-21st-century-principals/

Edsys. (2016). 10 Awesome Tips to Manage School

Discipline Issues. Retrieved June 29, 2019, from https://www.edsys.in/10-awesome-tips-tomanage-school-discipline-issues/

Educational Leaders. (2019). Guides for managing your school. Retrieved June 21, 2019, from http://www.educationalleaders.govt.nz/Managing -your-school/Guides-for-managing-your-school

Fidiana, W., Istiana, Z., Rosyidah, E., \& Purnomo, A. (2017). MINU Waru 2 Insan Berkilau Cahaya Manfaat. In Wirausaha Pendidikan Indonesia (Jilid 4). Sidoarjo: UNUSIDA Press. 
Irawan, D. E., Purnomo, A., Sutiksno, D. U., Abraham, J., Alamsyah, A., Saputra, D. H., ... Rosyidah, E. (2018). Kajian Pendidikan Tinggi IDRI untuk DPR RI dan Ristek Dikti 2018. Bandung: ITB Press.

Iskandar, A., Rizal, M., Kurniasih, N., Sutiksno, D. U., \& Purnomo, A. (2018). The Effects of Multimedia Learning on Students Achievement in Terms of Cognitive Test Results. Journal of Physics: Conference Series, 1114(1), 012019. https://doi.org/10.1088/17426596/1114/1/012019

Maula, I., Asitah, N., Munjidah, A., Nahdiyah, K., Yuniarti, D., Sholichah, S. A., ... Qori'ah, S. (2018). Kontribusi Kreativitas Guru SD dalam Induksi Pembelajaran.

https://doi.org/http://doi.org/10.17605/OSF.IO/B S795

Maula, I., Mufidah, F. I., Rosyidah, E., \& Purnomo, A. (2017). SD Antawirya Islamic Javanese School Mother is Culture. In Wirausaha Pendidikan Indonesia (Jilid 1). Sidoarjo: UNUSIDA Press. Meador, D. (2019). 10 Things a Successful School Principal Does Differently. Retrieved June 27, 2019, from https://www.thoughtco.com/things-asuccessful-school-principal-does-differently3194532

Munjidah, A., Zannah, I. P. N., Purnomo, A., \& Rosyidah, E. (2017). MI Thoriqussalam Berpegang Kepada Rosul. In Wirausaha Pendidikan Indonesia (Jilid 4). Sidoarjo: UNUSIDA Press. 
Nahdiyah, K., Amrina, S., Purnomo, A., \& Rosyidah, E. (2017). SD Taman Pendidikan Islam Porong Iman Kuat Bekal di Akhirat. In Wirausaha Pendidikan Indonesia (Jilid 2). Sidoarjo: UNUSIDA Press.

Purnomo, A. (2017). Pengertian Edupreneur. https://doi.org/10.31227/osf.io/8fnu6

Qori'ah, S., Sholichah, S. A., Purnomo, A., \& Rosyidah, E. (2017). Progresif Bumi Sholawat dengan Kebenaran Semua Pasti Ada Jalan. In Wirausaha Pendidikan Indonesia (Jilid 3). Sidoarjo: UNUSIDA Press.

Sholichah, S. A., Istiqomah, A., Rosyidah, E., \& Purnomo, A. (2017). MI Darun Najah Berfikir Berkarya Berdzikir. In Wirausaha Pendidikan Indonesia (Jilid 3). Sidoarjo: UNUSIDA Press.

Springer. (2019). Tips for Managing Organization.

Retrieved July 1, 2019, from

https://www.springer-ld.org/springer-

experience/center/parent-programs/tips-

organization

Suci, S. H. A., Rosyidah, E., Asitah, N., Aini, N., Murni, A. W., Anam, F., ... Kuraesin, A. D. (2018). Learning from Picture and Picture Action Research : Enhancement of Counting Ability on Division of Numbers for Primary School Students. Journal of Physics: Conference Series, 1114(1), 012044.

https://doi.org/10.1088/1742-

6596/1114/1/012044

Watanabe-Crockett, L. (2018). The 10 School Leadership Best Practices That Make a Difference. Retrieved June 22, 2019, from https://www.wabisabilearning.com/blog/10school-leadership-best-practices 
Yuniarti, D., Kautsari, M. F., Sholichah, F., Purnomo, A., \& Rosyidah, E. (2017). SMP SMA Al-Amin Ponpes Bahrul Hidayah Serahkan pada Allah Ta'ala. In Wirausaha Pendidikan Indonesia (Jilid 1). Sidoarjo: UNUSIDA Press. 